\title{
Flexible Assessment in Digital Teaching-Learning Processes: Case Studies via Computational Thinking
}

\author{
Amanda Argou ${ }^{1}$, Catherine Gayer ${ }^{1}$, \\ Simone Cavalheiro ${ }^{1}$, Luciana Foss ${ }^{1}$, André Du Bois ${ }^{1}$, Renata $^{\text {Reiser }}{ }^{1}$ \\ ${ }^{1}$ Federal University of Pelotas (UFPel) \\ Center for Technological Development (CDTEC) \\ CEP - 96.010-610 - Pelotas - RS - Brazil \\ \{aacardozo, catherine.gayer, simone.costa, lfoss, dubois, reiser\}@inf.ufpel.edu.br
}

\begin{abstract}
This proposal presents three applications: (i) the F-ATL methodology expressing the uncertainty inherent in assessment of teaching-learning (ATL) processes; (ii) two case studies validating the F-ATL methodology via activities of Computational Thinking (CT) applying fuzzy logic and the interval-valued fuzzy logic; (iii) the impact analysis related to the validation of both case studies. This proposal also focuses on modelling uncertainty in the assessment of digital educational resources and technologies in ATL processes, regarding the development of relevant thinking skills via CT. The case studies classify the students' marks in elementary school, evaluating their performance and considering CT skills as algorithm, generalization, abstraction, decomposition and evaluation.
\end{abstract}

\section{Introduction}

Computational Thinking (CT) (Wing 2006) is a method based on Computer Science (CS) which systematizes the solving process of problems based on three basic concepts: abstraction, automation and analysis (ISTE 2014). It is conceived as a method to develop competences such as logical organization and algorithmic information, represented by models and can also be manipulated by simulations. It seeks to stimulate various skills such as algorithmic reasoning, improving the development of logical properties as identifying, comparing, combining, analyzing, interpreting, applying and generalizing. Although CT plays an important role in developing logical reasoning, it demands to evaluate relevant and extremely subjective skills in school works. So, it should consider the uncertainty measure involved in assessing the digital teaching-learning (ATL) processes.

Traditional models to evaluate student usually apply average grades (arithmetic, geometric, weighted) in partial evaluations, providing a limit value to indicate student's failure or approval. It also generates an abrupt division resulting on cases where, having adopted a threshold equal to 6.0, a student with a 5.9 mark is failed, while another with a 6.0 mark is approved. It seems opportune to adopt more flexible models by making a "smoother" transition between such concepts of failure and approved but also supported on mathematical models. It is a common practice to adopt qualifying terms by linguistic variables (LV) such as regular and good to evaluate a criterion and later, to obtain a final grade translating a mark to a grade expressed as a linguistic term (LT).

The use of systems based on Fuzzy Logic (FL) (Zadeh 1965) presents itself as an alternative for student evaluation, making the modeling more flexible and incorporating 
VIII Congresso Brasileiro de Informática na Educação (CBIE 2019)

Anais do XXX Simpósio Brasileiro de Informática na Educação (SBIE 2019)

imprecise or uncertain information. Timely, fuzzy systems make use of expert knowledge, through their LV and their set of rules. In order to increase knowledge, the decision maker makes use of logic rules obtaining reliable information for a decision making.

Focusing on the uncertainty modeling in the ATL processes and regarding the development of relevant competences from $\mathrm{CT}$, this proposal is formalized as a fuzzy model named as F-ATL: Fuzzy System for Assessment in Teaching/Learning Processes. In this work, flexible assessment is concerned to a soft transition among the concepts from approval to non-approval. Noteworthy, three main applications are developed: (i) the FATL method, expressing the uncertainty inherent in competency-based on ATL processes; (ii) two case studies via CT validating the F-ATL method and its interval extension named IvF-ATL, expressing not only the uncertainty inherent in the assessment instruments in school works but also the gain adopting linguist terms related to skills promoted by CT; (iii) the impact analyse related to two case studies validating the F-ATL method, evaluating performance of students from elementary school based on CT skills as algorithm (Al), generalization (Ge), abstraction (Ab), decomposition (De) and evaluation (Ev).

The F-ATL proposal displays two components: (i) the FL-based model, modeling the uncertainties inherent of linguistic terms of CT skills in ATL processes; (ii) its interval extension, based on the Interval-valued Fuzzy Logic, a multi-valued fuzzy logic adding the imprecision modeling of multiple specialists (teachers, pedagogues, trainees and other educators) to quantify variables of CT skills in ATL processes.

\section{Computational Thinking}

The ability to think algorithmically, to seek the decomposition solving the parts and recomposing the result, to think of generalization, to identify and make use of patterns, to promote abstractions choosing well representations are all said to be essential to stimulate the achievement of thinking skills which are essential to students' educational development $(\mathrm{XX})$. The skills highlighted in this work are given as follows:

1. Algorithm (Al): increasing definition of steps, stimulating sequentially capability and understanding rule problems in order to get a solution.

2. Generalization(Ge): associating data and applying the definition of patterns, similarities and connections, resolution for general problems based on previous solutions and experiences.

3. Decomposition(De): analyzing subproblems which can be understood and solved independently, simplifying the total resolution aggregating partial solutions.

4. Evaluation(Ev): ensuring that a solution, whether an algorithm, a system or a process is efficient and appropriate for the solution problem;

5. Abstraction(Ab): considering the ability to make a manufactured product more understandable by reducing unnecessary details.

The F-ATL system presented in the next section innovates by applying the advantages of a formal model enabling two fuzzy logic approaches, providing flexible evaluation for classifying students and also regarding the development of these CT skills.

\section{Fuzzy Logic Approaches}

Taking advantage of such powerful techniques for the treatment of imprecise information, this work considers to contribute for the assessment in the digital education area. 
VIII Congresso Brasileiro de Informática na Educação (CBIE 2019)

Anais do XXX Simpósio Brasileiro de Informática na Educação (SBIE 2019)

The fuzzy set modeling is based on data extracted from expertise in CT and digital education specialists. Thus, in a fuzzy approach, a given element can belong to all fuzzy sets with distinct membership degrees in the range of the unitary interval [0,1] (Zadeh 2008). And, the zero degree indicates a complete exclusion and the one degree, complete inclusion. Intermediate degrees are obtained by membership functions, generalizing the characteristic functions in LC.

\subsection{F-ATL: Type-1 Fuzzy Logic Approach}

A fuzzy set (FS) $A=\left\{\left(x, \mu_{A}(x)\right) \mid x \in U\right.$ and $\left.\mu_{A}(x) \in[0,1]\right\}$, with $\mu_{A}: U \rightarrow[0,1]$ defined in the non-empty universe $U$, the membership function (MF) and $\mu_{A}(x)$ provides the membership degree (MD) of $x$ in $A$. In such context, the linguistic variables (LV) are assigned to linguistic terms (LT) in F-ATL system, defined by a triangular/trapezoidal MF and often presented as triangular $(\mathrm{A}=(a, b, c))$ or trapezoidal $(\tilde{A}=(a, b, c, d))$ forms, and related analytical expression is respectively given by Eq.(1) and Eq.(1) in the following:

$$
\mu_{A}(x)=\left\{\begin{array}{cc}
0, \quad \text { if } x \leq a ; \\
\frac{x-a}{b-a}, \quad \text { if } a<x \leq b ; \\
\frac{c-x}{c-b}, \quad \text { if } b \leq x<c ; \\
0, \quad \text { if } x \geq c .
\end{array} \quad \mu_{A}(x)=\left\{\begin{array}{cc}
\frac{x-a}{b-a}, & \text { if } a \leq x<b ; \\
1, & \text { if } b \leq x \leq c ; \\
\frac{d-x}{d-c}, & \text { if } c<x \leq d ; \\
0, & \text { otherwise. }
\end{array}\right.\right.
$$

A systematic review showing an overview of published articles in Brazilian congresses/journals in computation and using FL for evaluating and promoting ATL processes is reported in (Avila et al. 2017). Following such projects, this work also consider Mamdani fuzzy inference systems and, in the defuzzification step, the Centroid and Ordered Weighted Average (OWA) operators are also considered (Gehrke et al. 1996).

\subsection{IvT-ATL Interval-valued Fuzzy Logic Approach}

The Type-2 Fuzzy Set Theory was introduced by Zadeh in 1975 as an extension of the fuzzy set theory (Type-1), bypassing the recurrent problem of FL failure in modeling the uncertainties inherent in defining the membership functions of the antecedents and consequent on fuzzy inference systems (Mendel 2001). Also restrictive is the averagebased approach to the often distinct views of various experts (Karnik et al. 1999).

In the IvF-ATL proposal, Interval-valued Fuzzy Logic (IvFL) is considered based on Interval-valued Fuzzy Set (IvFS) theory (Gehrke et al. 1996), associating the membership degree of an element $x \in U$ to an interval $X=\left[\underline{\mu_{A}(x)}, \overline{\mu_{A}(x)}\right]$. Thus, IvFL can model vagueness with an additional ability to consider imprecision as two important aspects of uncertainty, reflecting this uncertainty by the length of the interval membership degree possibly provided by multiple education specialists and CT experts. In this approach, we do not consider only the averages but also the lowest (highest) evaluation from a specialist related to the infimun (supremun) of an interval.

Let $L([0,1])$ be the set of all real intervals in the unitary interval $[0,1]$ and the Kulish-Miranker partial order: $X \leq Y$ iff $\underline{X} \leq \underline{Y}$ and $\bar{X} \leq \bar{Y}, \forall X, Y \in L([0,1])$. By (Gehrke et al. 1996), a function $\mathbb{T}(\mathbb{S}): L([0,1])^{2} \rightarrow L([0,1])$ is an interval-valued t-norm $(t$ conorm) if it is commutative, associative, monotonic w.r.t. the partial order $\leq_{L([0,1])}$, with $\mathbf{1}=[1,1](\mathbf{0}=[0,0])$ as the neutral element. These functions qualify fuzzy intersections and unions as follows: $\operatorname{Min}(X, Y)=[\min (\underline{X}, \underline{Y}), \min (\bar{X}, \bar{Y})]$ and $\operatorname{Max}(X, Y)=$ $[\max (\underline{X}, \underline{Y}), \max (\bar{X}, \bar{Y})]$. Additionally, an interval function $\mathbb{N}: L([0,1]) \rightarrow L([0,1])$ is an 
VIII Congresso Brasileiro de Informática na Educação (CBIE 2019)

Anais do XXX Simpósio Brasileiro de Informática na Educação (SBIE 2019)

interval-valued fuzzy negation if, for all $X, Y \in L([0,1])$, it holds that: (i) $\mathbb{N} 1: \mathbb{N}(\mathbf{0})=\mathbf{1}$ and $\mathbb{N}(\mathbf{1})=\mathbf{0}$; and (ii) $\mathbb{N} 2$ : If $X \geq Y$ then $\mathbb{N}(X) \leq \mathbb{N}(Y)$.

The system IvF-ATL can estimate input and output functions by interval techniques. See Figure 1, graphically presenting its architecture briefly described as follows:

(1) Fuzzification Interface, inserting the uncertainty regarding the input membership function associating an input to an interval value;

(2) Rules Base, composing and classifying LV according to the IvFSs.

developed to be easily understandable and extensive, by adding new rules: (i) LV denoting FS, turning the modelling closer to the real world system; (ii) The type "AND" connections are taken into account to create the relationship among the input variables; (iii) The type of implications generalized modus ponens (affirmative): "if $\mathrm{X}$ is $\mathrm{A}$, then $\mathrm{Y}$ is B".

(3) Logic Decision Unity, performing inference system acting on aggregation fuzzification values by action of base rule system and combinations via fuzzy implication method (Liang and Mendel 2000);

(4) Defuzzification, considering two main stages: (i) Type Reducer operator, transforming an IvFS into FS, as the best fuzzy set representing the IvFS satisfying the following premise: when uncertainties disappear, the result of interval-valued based rule fuzzy system (IvFS) is reduced to a type-1 fuzzy system (T1FS) (Cabrera 2014); (ii) Output data: obtained as an average between $y_{L}$ and $y_{R}$.

In this work, values $y_{L}$ and $y_{R}$ were calculated using the iterative method of Karnik and Mendel (KM algorithm). Therefore, defuzzification step can still be obtained through the use of a conventional method such as the centroid, resulting in the final value.

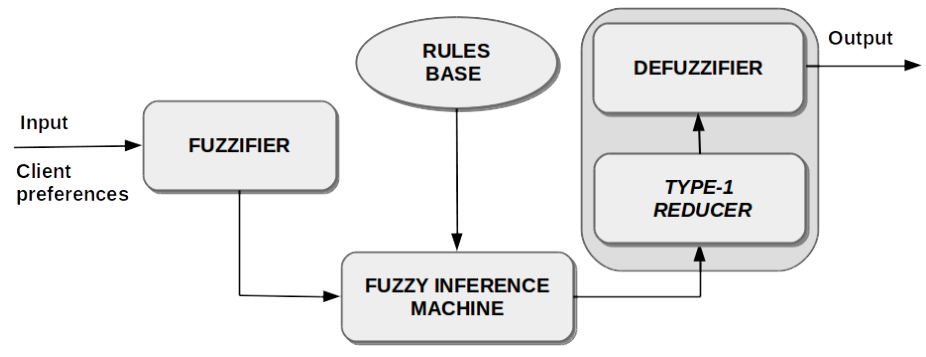

Figure 1. Interval-valued Fuzzy Inference System Architecture

\section{F-ATL Methodology}

The application of F-ATL model considers two relevant methodological steps, delimiting the sample space and constructing the fuzzy inference system aiming to evaluate learning through the development of thinking skills.

\subsection{Delineation of the Assessment in F-ATL}

Considering the student profiles to evaluate the learning of competences and thinking skills through training of logical/cognitive abilities.

1. Definition of student profiles (number, class, schedules, shifts);

2. Definition of institutional profile (type of school, place of access, attendance shift, disciplines available in the curriculum basis, competencies previously defined by management bodies/educational guidance); 
VIII Congresso Brasileiro de Informática na Educação (CBIE 2019)

Anais do XXX Simpósio Brasileiro de Informática na Educação (SBIE 2019)

3. Collection of class information (frequency, participation, attendance, etc.) and analysis of previously dominant skills considering competences and factors relevant to evaluation of student performance;

4. Quantifying the analysis of assessment instruments, for all selected contents, considering profiles previously identified;

5. Qualifying the analysis of assessment instruments, via thinking skills associated with CT considering the help of expertise/specialists;

6. Selection of normalization applied to collected data based on previous steps.

\subsection{Modeling uncertainty in decision making of digital educational assessments}

Structuring the F-ATL system for student assessments in teaching and learning processes, regarding student's performance with respect to relevant competences via CT.

1. Identification of the fuzzification strategies: (a) Selecting the fuzzy approach: type-1 fuzzy logic (T1FL) or interval-valued fuzzy logic, as type-2 fuzzy logic (T2FL) approaches; (b) Defining input and discretization data; (c) Determining linguistic terms for skills along with their respective scores, with the help of experts/specialist;

2. Identification of linguistic variables (LV) and corresponding fuzzy values (FV): (a) Selecting MF for each FV for the whole LV; (b) Defining MF for each FS, including the fuzzy partition of input/output spaces; (c) Verifying fuzzy set completeness guaranteeing normalization (sum 1) of degrees in MF of each LV.

3. Fuzzy rule base structure: (a) Selecting input/output variables of fuzzy control rules; (b) Choosing types of fuzzy control rules; (c) Generating the derivation related to fuzzy control rules; (d) Verifying consistency and completeness of control rules in interval-valued base rules (IvBR) and type-1 fuzzy base rules (T1BR).

4. Logical decision structure in a fuzzy inference system: (a) Selecting the most compatible fuzzy connectives (union, intersection, complementary operations) with the fuzzy implication method; (b) Interpreting the disjunction/conjunction via (co) triangular norms; (c) Selecting the mechanism of inference (Modus Ponens Generalized) via fuzzy implication method.

5. Consolidation of the output data interpretation and defuzzification strategies: (a) Reporting the defuzzification step based on output membership values; (b) Selecting an output given as the average of limit points of an interval value; (c) Selecting a method to the defuzzification step (max membership principle, centroid, weighted average, mean max);

6. Performing the type reducer and transforming an IvFSs into fuzzy sets: (a) Providing an output given as the average of limits points; (b) Eliminating the uncertainty, reducing IvBR into T1BR.

\section{Case Study F-ATL: Tipe-1 Fuzzy Logic Approach}

This study made use of data and resources collected from the XX Project, where the delineation of this proposal assessment based on F-ATL methodology was conceived. It was applied considering data of three classes of the fifth year of elementary school in municipal schools, which were based on playing ludic and unplugged activities, organized by two tests in the context of an academic project: (i) the pre-test (PeT), solved by the students before the contact with the activities developed in the classroom; and (ii) the 
VIII Congresso Brasileiro de Informática na Educação (CBIE 2019)

Anais do XXX Simpósio Brasileiro de Informática na Educação (SBIE 2019)

post-test (PoT), applied at the end of the activities. Both consisting of the same evaluation and containing eight questions addressing the five thinking skills measured by education specialists based on distinct criteria.

\subsection{F-ATL Data Modeling}

See in Table 1, lines (sum 1.0) referring to quantify a skill/question attributed by a specialist; and column 1 identify the quaetion, and the other columns are quantifying each skill related to each question in the test. So, the weighted vector skill/question is: [3.5 (Al), $0.9(\mathrm{Ge}), 0.8(\mathrm{De}), 1.8(\mathrm{Ab}), 1.0(\mathrm{Ev})]$.

Table 1. Weight of skills per issue

\begin{tabular}{clllll}
\hline Question & Al & Ge & De & Ab & Ev \\
\hline 1 & 0.5 & 0 & 0 & 0 & 0.5 \\
2 & 0.5 & 0 & 0 & 0 & 0.5 \\
3 & 0 & 0.4 & 0.3 & 0.3 & 0 \\
4 & 0 & 0.5 & 0 & 0.5 & 0 \\
5 & 0.5 & 0 & 0.5 & 0 & 0 \\
6 & 0 & 0 & 0 & 1 & 0 \\
7 & 1 & 0 & 0 & 0 & 0 \\
8 & 1 & 0 & 0 & 0 & 0 \\
\hline
\end{tabular}

After the normalization process, the vector of question/weight in the text $T=$ $(1 ; 1.5 ; 1.5 ; 1.2 ; 1.6 ; 1.2 ; 1 ; 1)$ applied to column 1 of Table 1 results on the vector $(0.5 ; 0.75 ; 0 ; 0 ; 0.8 ; 0 ; 1.0 ; 1.0)$, whose sum $(4.05)$ defines the maximum grade related to skill $\mathrm{Al}$ in the text. Analogously, the maximum grades for the other skills are obtained, generating the vector $[4.05(\mathrm{Al}), 1.2(\mathrm{Ge}), 1.25(\mathrm{De}), 2.25(\mathrm{Ab}) \mathrm{e} 1.25(\mathrm{Ev})]$, referring to the membership values qualifying the LV in the student evaluation as the maximum scores presented in Tables 2, 3, 4 and 5, in the next subsection. Thus, a student's performance is converted into LT and by aggregation generating the corresponding fuzzy mean. This project considered the operator OWA (Yager 2004), given as $O W A(\vec{x})=\sum_{j=1}^{n} w_{j} x_{i}$, for an ordered vector $\vec{x}=\left(x_{1}, \ldots, x_{n}\right)$ and normalized weight vector $\vec{w}=\left(w_{1}, \ldots, w_{n}\right)$.

\subsection{F-ATL Data Base: Membership Functions}

This decision making methodology is based on multiple assessment instruments, considering multiples attributes, regarding the individual performance in each thinking skill which is quantified by a specialist. It is able to convert linguistic variables into linguist terms, defining their corresponding membership functions.

In skill modeling input data related to $\mathrm{Al}$ and $\mathrm{Ab}$ and Performance $(\mathrm{P})$ as the output data, five linguistic terms were considered: Very Satisfactory (VS), Satisfactory (S), Regular (R), Unsatisfactory (U) and Very Unsatisfactory (VU) graphically presented in Figure 2. For grades obtained in the Ge, De and Ev (input data) three linguistic terms were considered: Satisfactory (S), Regular (R), Unsatisfactory (U), graphically shown in Figure 3. This structure implies in the set of $5^{2} \cdot 3^{3}$ rules in the inference system.

In Tables 2 e 3, the correspondence between LV and LT, graphically identifying membership functions defining the fuzzy sets related to $\mathrm{Al}$ and $\mathrm{Ab}$ skill modelings. See, e.g., a student with an Al rating is related to a Regular LT and a LV equal to 0.6. Analogously, Tables 4 and 5 express the relation between LT and LV for Ge, De and Av skills. 


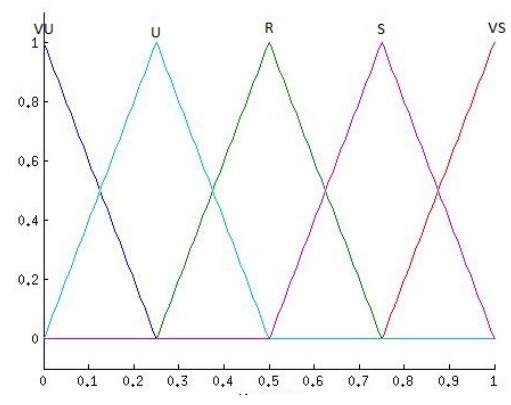

Figure 2. VL related to $A I, A b$ and $P$

Table 2. Scores: Skill AI

\begin{tabular}{lll}
\hline Scores & LT & LV \\
\hline $\mathrm{x} \leq 0.8$ & VU & 0.2 \\
$0.8<\mathrm{x} \leq 1.6$ & $\mathrm{U}$ & 0.4 \\
$1.6<\mathrm{x} \leq 2.4$ & $\mathrm{R}$ & 0.6 \\
$2.4<\mathrm{x} \leq 3.2$ & $\mathrm{~S}$ & 0.8 \\
$3.2<\mathrm{x} \leq 4.05$ & $\mathrm{VS}$ & 1.0 \\
\hline
\end{tabular}

Table 4. Scores: Skill Ge

\begin{tabular}{lll}
\hline Score & LT & LV \\
\hline $\mathrm{x} \leq 0.4$ & $\mathrm{U}$ & 0.3 \\
$0.4<\mathrm{x} \leq 0.8$ & $\mathrm{R}$ & 0.6 \\
$0.8<\mathrm{x} \leq 1.2$ & $\mathrm{~S}$ & 1.0 \\
\hline
\end{tabular}

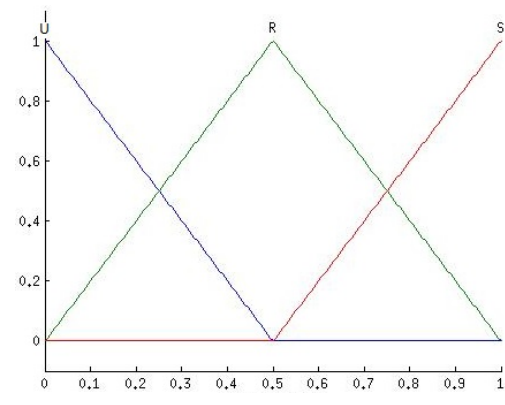

Figure 3. VL related to Ge, De e Ev

Table 3. Scores: Skill Ab

\begin{tabular}{lll}
\hline Score & LT & LV \\
\hline $\mathrm{x} \leq 0.45$ & VU & 0.2 \\
$0.45<\mathrm{x} \leq 0.9$ & $\mathrm{U}$ & 0.4 \\
$0.9<\mathrm{x} \leq 1.35$ & $\mathrm{R}$ & 0.6 \\
$1.35<\mathrm{x} \leq 1.8$ & $\mathrm{~S}$ & 0.8 \\
$1.8<\mathrm{x} \leq 2.25$ & $\mathrm{VS}$ & 1.0 \\
\hline
\end{tabular}

Table 5. Scores: Skill De e Ev

\begin{tabular}{lll}
\hline Score & LT & LV \\
\hline $\mathrm{x} \leq 0.42$ & $\mathrm{U}$ & 0.3 \\
$0.42<\mathrm{x} \leq 0.84$ & $\mathrm{R}$ & 0.6 \\
$0.84<\mathrm{x} \leq 1.25$ & $\mathrm{~S}$ & 1.0 \\
\hline
\end{tabular}

\subsection{L-ATL: Application and Main Results}

In Table 6, results of execution rules (scoring) from a sample of 5 in the group of 53 evaluated students are reported, including marks from those who have improved, maintained, or failed in test performance in the application of F-ATL. For the student S26, referring to five evaluated skills described from Table 2 to Table 5, we can express an increase in his learning activities, analysing the next data qualifying his school performance:

PeT: $L V_{S 26}=(0.6,1.0,1.0,0.6,0.6)$ related to vector $L T_{S 26}=\{\mathrm{R}, \mathrm{VS}, \mathrm{S}, \mathrm{R}, \mathrm{R}\}$; and PoT: $L V_{S 26}=(0.8,1.0,1.0,1.0,1.0)$ related to vector $L T_{S 26}=\{\mathrm{S}, \mathrm{VS}, \mathrm{S}, \mathrm{S}, \mathrm{S}\}$.

The grade/student ranking, resulting from the product of each line $(L V)$ to the relevance/vector $R=(0.4 ; 0.2 ; 0.2 ; 0.1 ; 0.1)$, quantifying a school performance based on thinking skills via CT which is planned to be applied considering the development of school activities in the period between PeT and PoT. See, for student S26:

$P_{e} T_{S 26}=((0.6)(0.4)+(1)(0.2)+(1)(0.2)+(0.6)(0.1)+(0.6)(0.1)) 10=7.6$; $P_{o} T_{S 26}=((0.8)(0.4)+(1)(0.2)+(1)(0.2)+(1)(0.1)+(1)(0.1)) 10=9.2$.

\section{Case Study IvF-ATL: Interval-valued Fuzzy Logic Approach}

The model IvL-ATL is able to model the uncertainty in assessment tools as well as the distinct opinions (two) specialists to rank the thinking skills compounding questions in both, PeT and PoT texts besides the frequency analysis. The prototype IvL-ATL is implemented based on toolbox (Castro et al. 2007), based on interval extensions of the Mamdani method and compositional relationship Max - Min (Castillo and Melin 2008). 
VIII Congresso Brasileiro de Informática na Educação (CBIE 2019)

Anais do XXX Simpósio Brasileiro de Informática na Educação (SBIE 2019)

Table 6. Summarizing Results of F-ATL Application

\begin{tabular}{c|ccccc|ccccc}
\multicolumn{9}{c}{ PeT } & \multicolumn{9}{c}{ PoT } \\
\hline Students & Al & Ge & De & Ab & Ev & Al & Ge & De & Ab & Ev \\
\hline S26 & 0.6 & 1 & 1 & 0.6 & 0.6 & 0.8 & 1 & 1 & 1 & 1 \\
S27 & 0.6 & 0.6 & 1 & 1 & 0.6 & 1 & 1 & 1 & 1 & 1 \\
S28 & 0.4 & 0.6 & 1 & 1 & 0.3 & 0.8 & 1 & 1 & 1 & 1 \\
S46 & 0.8 & 0.6 & 0.6 & 0.8 & 0.3 & 0.2 & 0.6 & 0.6 & 0.8 & 0.3 \\
S50 & 0.8 & 1 & 1 & 1 & 0.6 & 0.2 & 0.6 & 0.6 & 0.8 & 0.3 \\
\hline
\end{tabular}

\subsection{IvL-ATL: Modeling Data Base}

The most timely representation for lower and upper bound interval expressions of trapezoidal MF is graphically presented in Figures 4 and 5. Comparing with Figures 2 and 3, it is shown the appropriate inclusion of linear representation of the fuzzy approach in the domain of incertainty (DOU) as region characterizing the bi-dimensional representation in the interval-valued fuzzy approach. See in Table 7, the analytical expressions of MF modelling the thinking skills of Figure 4, Al, Ab and $\mathrm{P}$ which are associated to five LT. The other ones (Ge, De and Ev) associated to three LT can be analogously expressed.

Thus, the imprecision related to distinct experts' opinions quantifying a thinking skill in the text is represented by the diameter of an interval membership degree. In order to observe the reliability gain in use the IvF-ATL model, consider the expression in the first line in Table 8: in the fuzzy set $V U$ related to the thinking skill Al, taking $x=0,2$ in equations of line 1 , Table 7 . It results on the membership degree $\mu_{V U}(x) \in[0.101 ; 0.5336]$.

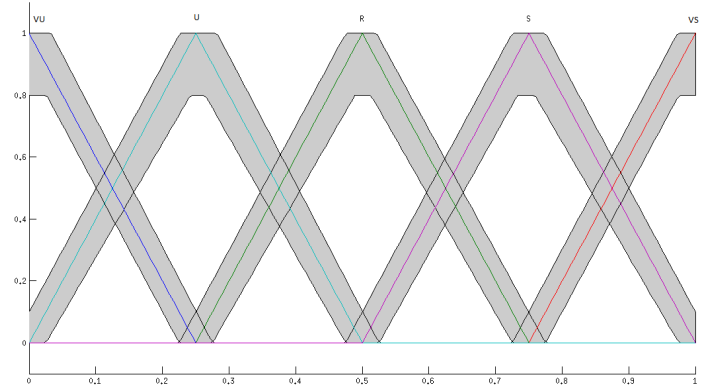

Figure 4. Skills Al, Ab.

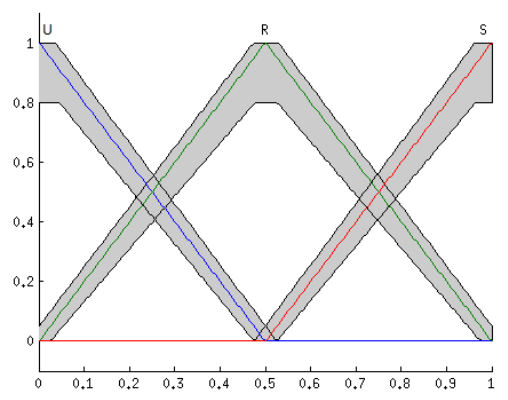

Figure 5. Skills Ge, De e Ev.

\subsection{IvF-ATL: Results and Analysis of Case Studies}

See, Table 8 showing the scoring from a sample of 11 in the group of 53 evaluated students in PeT and PoT. In particular, the OWA calculation with $\vec{w}=$ (0.45(Pet), 0.45(Pot $) 0.1($ Freq $))$ and the rule converting FV in TL are given as follows:

$$
\text { Rule }=(V S(x>9), S(8 \leq x \leq 9), R(6 \leq x \leq 8), U(5 \leq x \leq 6), V U(x<5)) .
$$

From results in Table 8, in column 4, we the following LV frequencies: 2 (VS) , 2 (S) , 4 (R), 1 (U) and 1 (VU). Using the OWA method, the analysis carried out more carefully, reducing the number of students with VS classification. Such decreasing occurs when a student does not reach an adequate frequency.

Results obtained by applying the IvF-ATL model are presented in Figure 6, where the arithmetic means (CL) and fuzzy averages (FL) are compared in a progressive evolution, increasing in one by one step in a range from 0 to 20 , reflecting their possibilities 
VIII Congresso Brasileiro de Informática na Educação (CBIE 2019)

Anais do XXX Simpósio Brasileiro de Informática na Educação (SBIE 2019)

Table 7. Algebraic Expressions of five LV for Al, Ab and $P$

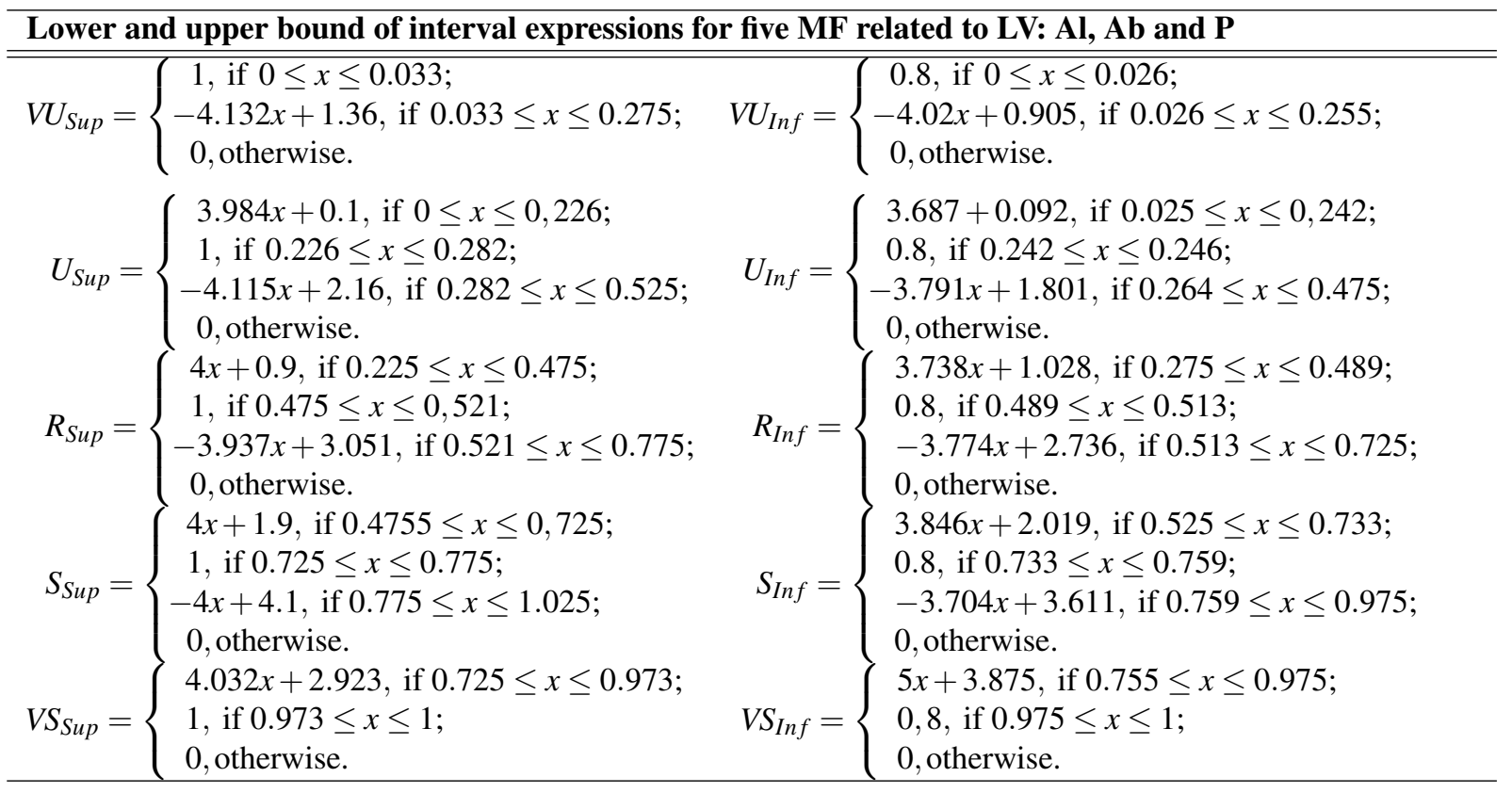

for the five value inputs from 0 to 10 . In the total of 20 marks, fuzzy averages are greater than arithmetic means in $90 \%$ of the total simulation and they are equal in $10 \%$. In general, the values of the fuzzy averages were $1.22 \times$ higher than the value of the arithmetic means. In addition, more significant data occurred in inputs from 16 onwards, being the grades obtained in an Al FS greater than other FS.

\section{CONCLUSION}

This proposal presents the interval approach of the F-ATL methodology modelling the uncertainty in the assessment of digital educational resources and technologies in ATL processes, regarding the development of relevant thinking skills via CT. The case studies classify the students' marks in elementary school, evaluating their performance and considering thinking skills. Further work extends this proposal, including new thinking skills

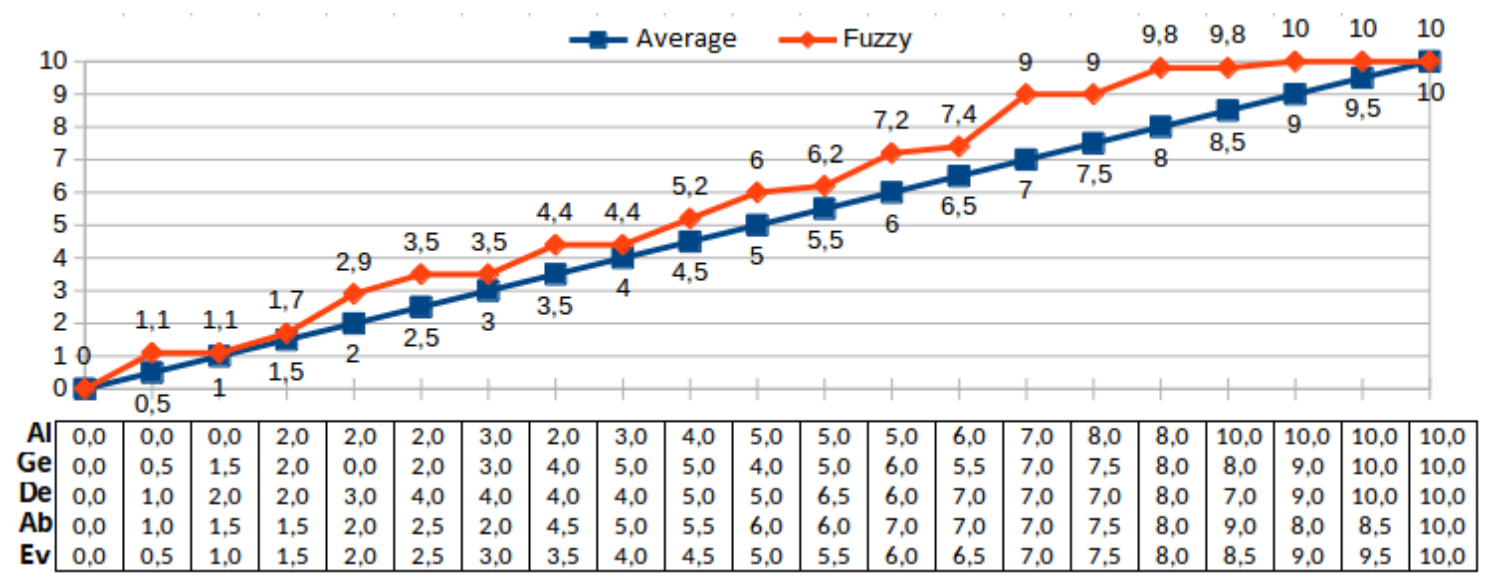

Figure 6. Comparative graph between arithmetic mean and Fuzzy 
VIII Congresso Brasileiro de Informática na Educação (CBIE 2019)

Anais do XXX Simpósio Brasileiro de Informática na Educação (SBIE 2019)

Table 8. Fuzzy Average related to Pet and Pot

\begin{tabular}{c|ccc|ccc}
\multicolumn{4}{c}{ Average } & \multicolumn{3}{c}{ Linguistc Terms } \\
\hline Students & Pet & PoT & Freq & PeT & PoT & Freq \\
\hline S20 & 8.20 & 9.60 & 8.90 & S & VS & S \\
S21 & 6.20 & 6.00 & 6.50 & R & R & R \\
S22 & 6.30 & 10.00 & 8.20 & R & VS & S \\
S23 & 2.50 & 5.00 & 4.40 & VU & U & VU \\
S24 & 4.30 & 5.60 & 5.40 & VU & U & U \\
S25 & 4.70 & 7.10 & 6.30 & VU & R & R \\
S26 & 6.10 & 9.20 & 7.80 & R & VS & R \\
S27 & 7.20 & 10.00 & 8.70 & R & VS & S \\
S28 & 8.40 & 10.00 & 9.30 & S & VS & VS \\
S29 & 9.20 & 9.20 & 9.30 & VS & VS & VS \\
S30 & 6.00 & 5.90 & 6.40 & R & U & R \\
\hline
\end{tabular}

as relevant variables using IvF-ATL method but also considering admissible linear orders to compare results directly from the list of intervals generated by the output system.

\section{References}

Avila, C., Cavalheiro, S., Bordini, A., Marques, M., Cardozo, M., and Feijo, G. (2017). Metodologias de avaliação do pensamento computacional: uma revisão sistemática. In SBIE 2017.

Cabrera, N. V. (2014). Aplicação da extensão de zadeh para conjuntos fuzzy tipo 2 intervalar. Dissertação (Mestrado em Ciências Exatas e da Terra), page $86 \mathrm{f}$.

Castillo, O. and Melin, P. (2008). Type-2 Fuzzy Logic: Theory and Applications, volume 223 of Studies in Fuzziness and Soft Computing. Springer.

Castro, J. R., Castillo, O., and Melin, P. (2007). An interval type-2 fuzzy logic toolbox for control applications. In FUZZ-IEEE, pages 1-6. IEEE.

Gehrke, M., Walker, C., and Walker, E. (1996). Some comments on interval valued fuzzy sets. International Journal of Intelligent Systems, 11(10):751-759.

ISTE (2014). Computational thinking in k-12 education leadership toolkit. Disponivel por WWW em ; http :// www. iste. org . $_{\text {. }}$

Karnik, N., Mendel, J., and Liang, Q. (1999). Type-2 fuzzy logic systems. IEEE Transactions on Fuzzy Systems, 7:643-658.

Liang, Q. and Mendel, J. M. (2000). Interval type-2 fuzzy logic systems: theory and design. IEEE Transactions on Fuzzy systems, 8:535-550.

Mendel, J. M. (2001). Uncertain Rule-Based Fuzzy Logic Systems: Introduction and New Directions. Prentice-Hal.

Wing, J. (2006). Computational thinking. Commun. of the ACM, 49(3):33-35.

Yager, R. R. (2004). On some new classes of implication operators and their role in approximate reasoning. Inf. Sci. Inf. Comput. Sci., 167(1-4):193-216.

Zadeh, L. A. (1965). Fuzzy sets. Information and Control, (8):338-358.

Zadeh, L. A. (2008). Is there a need for fuzzy logic? Inf. Sciences, 178(13):2751-2779. 